\title{
Adaptation of the mammary oxygen consumption in response to milking frequency variations in dairy cows
}

\author{
E. Delamaire and J. Guinard-Flament ${ }^{1}$ \\ INRA-Agrocampus Rennes, UMR Production du Lait \\ 35590 St. Gilles, France
}

\begin{abstract}
The aim of this experiment was to examine the adaptation of mammary energy expenditure in response to variations in milk yield induced by modifications of milking frequency. Three lactating cows were milked at 8-, 12-, 16- or 24-h intervals according to a Youden square with 5 periods of 7 days. When milking interval increased, milk yield decreased significantly by $24 \%$, mammary blood flow significantly by $16 \%$ and oxygen consumption not significantly by $18 \%$. As a result, the non significant decrease in the mammary oxygen consumption is associated with no reduction of the oxygen extraction but a decrease blood supply to the udder.
\end{abstract}

KEY WORDS: dairy cow, mammary gland, oxygen consumption, milking frequency

\section{INTRODUCTION}

Once daily milking leds to marked modifications of milk yield that can decrease to $30 \%$ compared to twice daily milking (Stelwagen, 2001). Such alteration of the milk components synthesis may involve a decrease of the mammary energy expenditure. Assuming that the udder oxygen $\left(\mathrm{O}_{2}\right)$ consumption is an indicator of energy expenditure, a study was conducted to determine the evolution of the mammary $\mathrm{O}_{2}$ consumption in response to increasing milking intervals. In addition, to understand how the quantity of $\mathrm{O}_{2}$ taken up by the udder is regulated, nycthemeral variations of mammary blood flow (MBF) and extraction of $\mathrm{O}_{2}$ were examined.

\section{MATERIAL AND METHODS}

Three multiparous lactating dairy cows in mid lactation were milked at 8-, 12-, 16- or 24-h intervals during the last 7 days of 2 week periods according to a

\footnotetext{
${ }^{1}$ Corresponding author: e-mail: flament@roazhon.inra.fr
} 
Youden square with 5 periods. One month before the beginning of the experiment, an ultrasonic flow probe (Transonic Systems Inc., Ithaca, NY) was implanted around the left external pudic artery and two permanent catheters were inserted into the left carotid and left subcutaneous abdominal vein (Rigout et al., 2002). Milk yield was measured daily during the experimental week as well as MBF, which was measured every minute.

The last day of each period, $\mathrm{O}_{2}$ kinetics were determined from 12 blood samples taken simultaneously from the carotid and the milk vein over $24 \mathrm{~h} . \mathrm{O}_{2}$ concentration was measured by a gas analyser (ABL 625, Radiometer, Copenhagen). The mammary $\mathrm{O}_{2}$ consumption was determined using the Fick principle (consumption $=\mathrm{MBF} \times$ arteriovenous differences $(\mathrm{AVD})$ of $\mathrm{O}_{2}$ ). Averaged data were analysed following analysis of variance using cow, period and treatment as sources of variation according to the GLM procedure of SAS. Additionally time of day and time of day $\mathrm{x}$ treatment interaction were added to the model to analyse kinetics data. Linear, quadratic and cubic responses of data were analysed by orthogonal contrasts.

\section{RESULTS}

Milk yield decreased curvilinearly from 37.7 to $28.7 \mathrm{~kg} / \mathrm{d}$ for 8 - and $24-\mathrm{h}$ milking intervals, respectively $(\mathrm{P}<0.01)$. Milk yield for 8 -h treatment was not different from $12-\mathrm{h}$ treatment $(37.8 \mathrm{~kg} / \mathrm{d})$ and was decreased by 3.9 and $9.1 \mathrm{~kg}$ per day for the 16- and 24-h intervals. After 7 days of treatment, the daily average MBF decreased linearly with increasing milking interval (from 7.02 to $5.79 \mathrm{~L} / \mathrm{min}$; $\mathrm{P}<0.01$ ). Kinetics analysis of the MBF showed significant effect of time of day and time of day $\mathrm{x}$ treatment interaction $(\mathrm{P}<0.01$ and 0.05 , respectively; Figure 1).

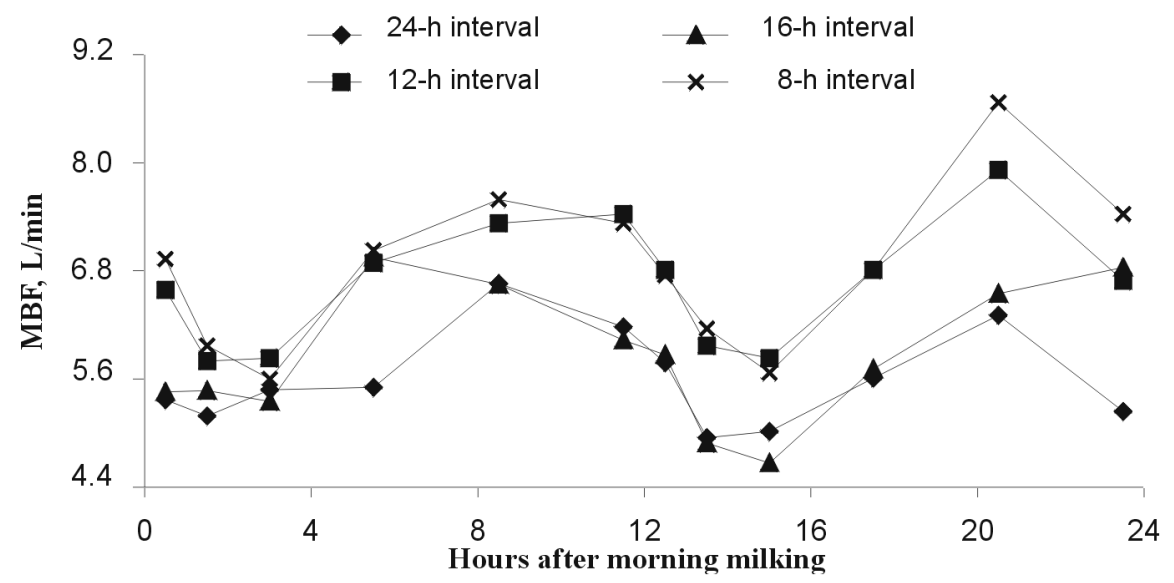

Figure 1. Nycthemeral kinetics of mammary blood flow (MBF) according to four milking intervals in dairy cows (time of day and time of day $\times$ treatment interaction: $\mathrm{P}<0.01$ ) 
Nycthemeral MBF kinetics curves were quite similar between treatments but MBF values were lower for 16- and 24-h treatments. After 7 days of treatment, the averaged $\mathrm{O}_{2}$ arterial concentration tended to increase linearly and cubicly by $4.5 \%$ in response to increased milking interval $\left(\mathrm{P}<0.1\right.$; Table 1). The averaged $\mathrm{O}_{2}$ AVD remained unchanged for all treatments.

Table 1. Mammary blood flow (MBF), oxygen arterial concentration, mammary arteriovenous difference (AVD) and consumption according to increasing milking intervals in dairy cows

\begin{tabular}{lccccccccc}
\hline & \multicolumn{4}{c}{ Milking interval, $\mathrm{h}$} & \multirow{2}{*}{ SEM $^{1}$} & \multicolumn{3}{c}{ Orthogonal contrast $^{2}$} \\
\cline { 2 - 5 } & 8 & 12 & 16 & 24 & & $\mathrm{~L}$ & $\mathrm{Q}$ & $\mathrm{C}$ \\
\hline MBF, L/min & 7.02 & 6.94 & 6.12 & 5.79 & 0.340 & 0.009 & 0.144 & 0.266 \\
Oxygen & & & & & & & & \\
$\quad$ arterial concentration, mmol/L & 5.96 & 5.84 & 6.17 & 6.12 & 0.101 & 0.052 & 0.173 & 0.052 \\
$\quad$ AVD, mmol/L & 1.68 & 1.75 & 1.75 & 1.69 & 0.173 & 0.869 & 0.540 & 0.937 \\
$\quad$ consumption, $\mathrm{mmol} / \mathrm{min}$ & 11.2 & 11.3 & 10.0 & 9.3 & 1.46 & 0.160 & 0.385 & 0.690 \\
\hline
\end{tabular}

${ }^{1}$ standard error of the mean

${ }^{2}$ linear (L), quadratic (Q) and cubic (C) effects

The mammary consumption of $\mathrm{O}_{2}$ decreased in response to treatments with increasing milking interval, but this was not significant (by $18 \%$ for $24-\mathrm{h}$ treatment compared to $12-\mathrm{h}$ treatment, $\mathrm{P}=0.16)$. Nycthemeral kinetics of $\mathrm{O}_{2}$ AVD were significant with time of day $(\mathrm{P}<0.01)$, variations being opposite to those of MBF (Figure 2). Nycthemeral kinetics analysis of $\mathrm{O}_{2}$ did not show a significant interaction between time of day and milking interval treatment.

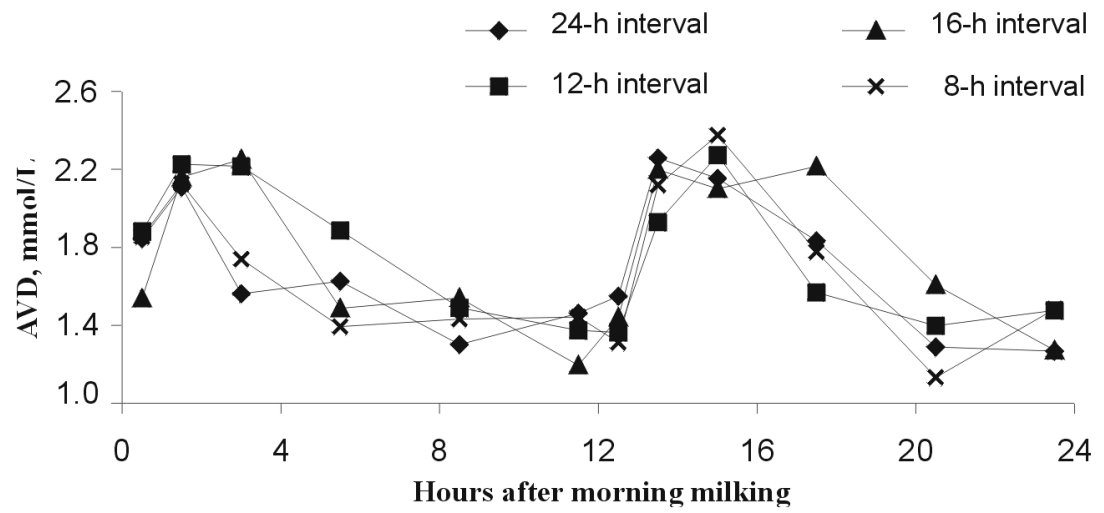

Figure 2. Nycthemeral kinetics of arteriovenous difference (AVD) of oxygen according to four milking intervals in dairy cows (time of day: $\mathrm{P}<0.01$ ) 


\section{DISCUSSION}

No significant variation in udder $\mathrm{O}_{2}$ consumption with changes in milking frequency was observed in this study probably because of an insufficient number of animals. However, amplitude of the impairments of $\mathrm{O}_{2}$ consumption and milk yield was quite similar (18 vs $24 \%$, respectively) suggesting that the energy expenditure of the udder is diminished in response to the milk yield reduction caused by the increase of milking intervals.

The decrease of the mammary oxidative activity seems to be solely associated with a reduction of mammary blood supply without any change in the mammary extraction of $\mathrm{O}_{2}$. Nycthemeral variations of MBF showed lower values throughout the day when milking interval increased. This result was previously reported by Guinard-Flament and Rulquin (2000) with dairy cows milked once daily. Prosser et al. (1996) supported the hypothesis of a regulation of the mammary blood flow by the udder that would regulate its blood supply to sustain its metabolism. In the present study, the udder could have reduced its blood supply to respond to the impairment of its ability to synthesise milk due to extended milking intervals.

\section{CONCLUSIONS}

The mammary gland seems to regulate its $\mathrm{O}_{2}$ consumption not by decreasing the $\mathrm{O}_{2}$ extraction but by significantly decreasing the blood supply in response to milk yield decreases due to milking frequency reduction.

\section{REFERENCES}

Guinard-Flament J., Rulquin H., 2000. Effect of once daily milking (ODM) vs twice daily milking (TDM) on the mammary blood flow in dairy cows. 5th Joint EAAP/ASAS Workshop on "Biology of Lactation in Farm Animals". August, 2000, La Haye (The Netherlands)

Rigout S., Lemosquet S., van Eys J.E., Blum J.W., Rulquin H., 2002. Duodenal glucose increases glucose fluxes and lactose synthesis in grass silage-fed dairy cows. J. Dairy Sci. 85, 594-606

Prosser C.G., Davis S.R., Farr V.C., Lacasse P., 1996. Regulation of blood flow in the mammary microvasculature. J. Dairy Sci. 79, 1184-1197

Stelwagen K., 2001. Effect of milking frequency on mammary functioning and shape of the lactation curve. J. Dairy Sci. 84, Suppl., E204-E211 